\title{
Dermatófitos e leveduras isolados da pele de cães com dermatopatias diversas*
}

\author{
Dermatophytes and yeasts isolated from the skin of dogs with diverse dermatopathies \\ Mauro Luís da Silva Machado ${ }^{1}$, Carin Elisabete Appelt² \& Laerte Ferreiro ${ }^{3}$
}

\begin{abstract}
RESUMO
As micoses cutâneas, causadas principalmente pelos dermatófitos Microsporum spp. e Trichophyton mentagrophytes e pelas leveduras Malassezia pachydermatis e Candida albicans, são as doenças fúngicas mais freqüentes que acometem os cães. O principal objetivo deste estudo foi conhecer a ocorrência desses fungos na pele de cães com dermatopatias de origens diversas. Uma população de 250 cães, com diferentes dermatoses, foi avaliada clinicamente no Serviço de Dermatologia do Hospital de Clínicas Veterinárias da Universidade Federal do Rio Grande do Sul, Porto Alegre - RS, no período de março de 2000 a março de 2001. Esses animais foram submetidos ao teste da lâmpada de Wood e obtiveram-se amostras de pêlo e/ou escamas da pele para exame de microscopia direta e cultivo fúngico. Foram também realizados outros exames complementares, quando disponíveis, no intuito de estabelecer o diagnóstico das diversas dermatopatias. As culturas fúngicas resultaram: 49,6\% sem isolamento e 50,4\% positivas, sendo isolados $29,6 \%$ fungos sapróbios e 20,8 \% fungos causadores de micoses cutâneas (13,2 \% Malassezia pachydermatis; 5,6\% Microsporum canis e 2,0\% Microsporum gypseum). As prevalências das dermatopatias, distribuídas por grupos de doenças, foram as seguintes: $44,4 \%$ de origem imunopática; $20 \%$ parasitária; $12,4 \%$ complexo seborréia-disqueratinização; $11,2 \%$ bacteriana; $6,4 \%$ fúngica; $2,8 \%$ diversas, $2,0 \%$ endócrina e $0,4 \%$ congênita e hereditária.
\end{abstract}

Descritores: cães, dermatófitos, leveduras, dermatopatias, micoses cutâneas, Microsporum sp., Malassezia pachydermatys.

\begin{abstract}
Cutaneous mycoses are the most common fungal skin diseases seen in dogs. The most frequently involved fungi are the dermatophytes Microsporum spp. and Trichophyton spp. and the yeasts Malassezia pachydermatis and Candida albicans. The aim of this study was report the occurrence of these fungi isolated from skin scrapings of dogs with diverse dermatopathies. A population of 250 dogs was clinically evaluated at the Hospital de Clínicas Veterinárias da Universidade Federal do Rio Grande do Sul, Porto Alegre - RS, Brazil, during the period from March - 2000 to March - 2001. The animals were examined under Wood's light and samples of hairs and skin scrapings were collected for direct microscopic examinations and mycological cultures. Culture examination yielded $49.6 \%$ negatives cultures and $50.4 \%$ positives ones, being $29.6 \%$ saprobic fungi and $20.8 \%$ potentially pathogenic fungi (13.2\% Malassezia pachydermatis and $7.6 \%$ Microsporum spp.). The prevalence of the dermatopathies, classified in groups of diseases, was: allergic and immune-mediated (44.4\%); parasitic (20\%); keratinization disorders (12.4\%); bacterial (11.2\%); fungal (6.4\%); miscellaneous (2.8\%); endocrine (2.0\%) and congenital/hereditary $(0.4 \%)$.
\end{abstract}

Key words: dogs, dermatophytes, yeasts, dermatopathies, cutaneous mycoses, Microsporum sp., Malassezia pachydermatys. 


\section{INTRODUÇÃO}

Os problemas dermatológicos em cães são reconhecidos como um dos principais motivos de visitas às clínicas veterinárias [15,22,25]. Dados de Hospitais Veterinários de Instituições de Ensino apontam índices de 9,94\% [21] até 18,8\% [23].

Entre as doenças de pele mais freqüentemente diagnosticadas encontram-se as de origem bacterianas, imunopáticas e endócrinas [15,23], sendo que no Brasil, as parasitárias também estão entre as mais freqüentes [13], entretanto, muitas dermatoses, nãoespecíficas, pruriginosas ou não, são diagnosticadas como micoses com base em evidências clínicas inadequadas [22].

Entre as micoses que afetam a pele de caninos, as mais comumente encontradas são as causadas por dermatófitos (Microsporum canis, M. gypseum e Trichophyton mentagrophytes) e por leveduras (Malassezia pachydermatis e Candida albicans).

Conforme dados da literatura brasileira e internacional, a ocorrência de dermatófitos em cães com dermatopatias diversas varia de $12,5 \%$ a $24,6 \%$ [1$3,19,24$ ] enquanto a ocorrência de Malassezia pachydermatis encontra-se em torno de 15,0\% $[6,9,17,20,24]$ e de Candida albicans em torno de $1,0 \%$, embora a participação de Candida spp. na etiologia de lesões de pele seja questionável $[7,24]$.

Os objetivos do presente trabalho foram conhecer a ocorrência de fungos causadores de micoses cutâneas na pele de cães com dermatopatias diversas e suas relações com idade, raça, sexo e o diagnóstico da dermatopatia, atendidos no Serviço de Dermatologia do Hospital de Clínicas Veterinárias da UFRGS.

\section{MATERIAIS E MÉTODOS}

Foram utilizados 250 cães com distúrbios dermatológicos diversos, atendidos Serviço de Dermatologia do Hospital de Clínicas Veterinárias da Universidade Federal do Rio Grande do Sul (HCV/UFRGS), no período de março de 2000 a março de 2001.

Dos 250 animais amostrados, $148(59,2 \%)$ eram fêmeas e $102(40,8 \%)$ machos; $71(28,4 \%)$ sem raça definida (SRD) e $179(71,6 \%)$ com raça definida (CRD); a faixa etária variou de 14 dias a 15 anos de idade, estando a maioria, $164(65,6 \%)$ concentrada na faixa de até quatro anos. Particularmente, o grupo da faixa etária até um ano de idade foi o mais representativo, com 75 animais (30\%). A média geral das idades foi de 3 anos e 7 meses.

Os animais foram resenhados, avaliados clinicamente de acordo com a sistemática do Serviço de Dermatologia do HCV/UFRGS e examinados com lâmpada de Wood em sala escura.

Foram obtidas amostras do pelame e/ou crostas das regiões afetadas para exames micológicos direto e cultura em todos os casos, de acordo com as normas técnicas do Laboratório de Micologia da Faculdade de Veterinária da UFRGS.

Os dados referentes à significação estatística foram avaliados por Teste de Associação, utilizandose o Qui-quadrado. Valores de $\mathrm{p}<0,05$ foram considerados significativos. A análise estatística foi efetuada através do software The Student Edition of Statistix, version 4.0.

\section{RESULTADOS}

Os resultados das culturas fúngicas foram os seguintes: $124(49,6 \%)$ culturas sem crescimento fúngico; 74 (29,6\%) culturas resultaram positivas para fungos considerados sapróbios e em 52 (20,8\%) culturas observou-se crescimento de fungos causadores de micoses cutâneas, sendo 33 (13,2\%) Malassezia pachydermatis, 14 (5,6\%) Microsporum canis e 5 (2,0\%) M. gypseum.

Os diagnósticos das dermatopatias dos 250 cães incluídos na amostragem, apresentados por grupos de doenças conforme a etiologia, bem como os resultados das culturas fúngicas positivas para fungos causadores de micoses cutâneas, estão demonstrados na Tabela 1.

\section{DISCUSSÃO}

As dermatopatias mais prevalentes, encontradas neste trabalho - arroladas por grupos de doenças, em ordem decrescente - foram: imunomediadas, parasitárias, complexo seborréia-disqueratinização, bacterianas, fúngicas, diversas, endócrinas e congênitas / hereditárias.

Esses dados, se comparados com os dispostos na literatura internacional e brasileira, encontram-se parcialmente concordantes. No Canadá são relatadas [23] como doenças comumente observadas em cães, 
TABELA 1. Freqüências ( $\mathrm{N}$ e \%) das dermatopatias e dos resultados das culturas positivas para fungos causadores de micoses cutâneas, em 250 cães atendidos no Serviço de Dermatologia do HCV/ UFRGS, Porto Alegre RS, no período de março de 2000 a março de 2001.

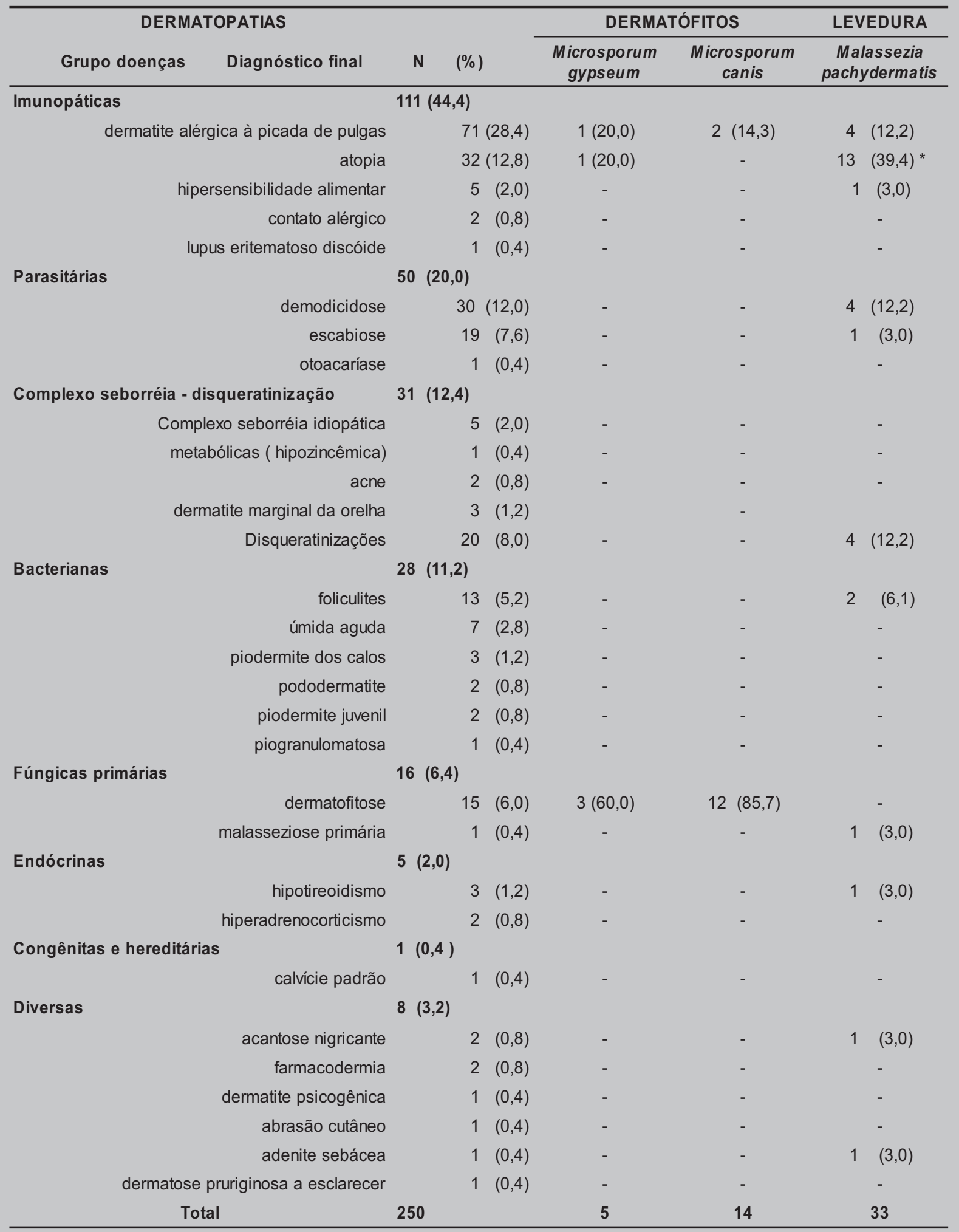

* = diferença estatisticamente significativa $(\mathrm{p}<0,05)$ de culturas positivas de Malassezia pachydermatis em cães com atopia , em relação às outras dermatopatias. 
as de origem bacterianas, imunológicas, endócrinas, neoplásicas e parasitárias. Entretanto, no Japão [15], citam-se as de origens bacterianas, alérgicas e endócrinas como as mais prevalentes. No Brasil [13], em apenas um trabalho realizado, relatam-se como as mais freqüentes, as de origem bacteriana, parasitária, fúngica e imunológica.

Analisando esses resultados, observa-se, se comparados os dados brasileiros aos internacionais que, no Brasil, as doenças parasitárias apresentam-se com alta prevalência, enquanto as endócrinas, com baixa prevalência.

O porcentual de $20,8 \%$ de fungos causadores de micoses cutâneas (7,6\% de dermatófitos e 13,2\% de Malassezia pachydermatis), encontrado neste trabalho é inferior aos índices relatados na literatura científica.

Foram isolados, dos 250 cultivos, $7,6 \%$ de dermatófitos (73,7\% Microsporum canis e 26,3\% M. gypseum). Comparativamente, a porcentagem total encontrada de dermatófitos neste trabalho está abaixo da descrita na literatura consultada(1-3,19,24). Já em relação à proporção de Microsporum canis $(73,7 \%)$ dentre os dermatófitos, está em conformidade com vários estudos realizados em cães com dermatopatias diversas $[2,19]$.

No tocante à predisposição sexual relativamente ao resultado das culturas positivas para dermatófitos, não foram encontradas diferenças estatisticamente significativas, confirmando os dados da literatura revisada .

Detectou-se maior número de culturas de dermatófitos em cães até um ano de idade, apesar de estatisticamente não ter havido diferença significativa. Tal fato está de acordo com a maioria dos trabalhos publicados

Quanto à predisposição racial, observou-se que os cães sem raça definida (S.R.D.) e os cães com definição racial, das raças Yorkshire (Figura 1) e Boxer (Figura 2), foram os mais representativos. Apesar do pequeno número de casos, 19 cães com culturas positivas para dermatófitos, os resultados são próximos aos mencionados pelos autores consultados.

O diagnóstico da dermatofitose foi firmado em 15 casos, embasado na história clínica, lesões sugestivas e confirmação por cultura fúngica. Por outro lado, quatro cães que apresentavam história clínica, sintomatologia e resposta terapêutica sugestivas de outras dermatoses não fúngicas, como dermatite alérgica à picada de pulgas (três casos) e atopia (um caso) (Figura 3), também tiveram suas culturas fúngicas positivas para dermatófitos.

A presença de dermatófitos na pele desses cães, sem aparente alterações clínicas compatíveis com dermatofitose, poderia ser ocasional, pois excetuando-se a dermatose que ora possuíam, poderiam ser considerados como simples portadores do dermatófito, pois de acordo com os dados da bibliografia consultada, o pelame de 1 até $19 \%$ de cães sem aparente lesões de pele podem albergar dermatófitos. Essas micoses poderiam, entretanto, estar associada à doença de base e apesar de não se ter encontrado nenhuma referência na literatura veterinária consultada sobre a associação de dermatófitos a outras dermatopatias, essa hipótese parece ser a mais plausível. Por se tratar de fungos patogênicos e representarem risco de contágio, todos esses cães foram tratados, também, topicamente com antimicóticos.

Não ocorreu crescimento de Candida spp. em nenhuma das 250 culturas fúngicas. Este resultado pode ser justificado pela raridade da sua presença em amostras de pêlos e escamas da pele de cães com dermatopatias diversas que, conforme a bibliografia consultada, não atinge a $1 \%[3,24]$.

Os $33(13,2 \%)$ isolados de Malassezia pachydermatis não pode ser comparado devido ao número reduzido de publicações indexadas sobre a presença de $M$. pachydermatis na pele de cães com dermatopatias diversas, e das diferentes técnicas utilizadas na identificação e quantificação das leveduras.

Ao serem cotejados os resultados das culturas de $M$. pachydermatis, com relação ao sexo dos cães utilizados na amostra, não foi encontrado diferença estatística significativa para predisposição sexual, o que está em conformidade com todos os trabalhos consultados.

Constatou-se maior porcentual $(24,2 \%)$ de culturas de $M$. pachydermatis nas amostras dos cães com idade até doze meses, embora essa diferença não tenha sido estatisticamente significante em relação às demais faixas etárias.

As culturas de $M$. pachydermatis foram mais freqüientemente obtidas de cães das raças Cocker, Pastor Alemão e Dachshund (Figuras 4 e 5), embora, tenha sido detectada diferença estatística significante 


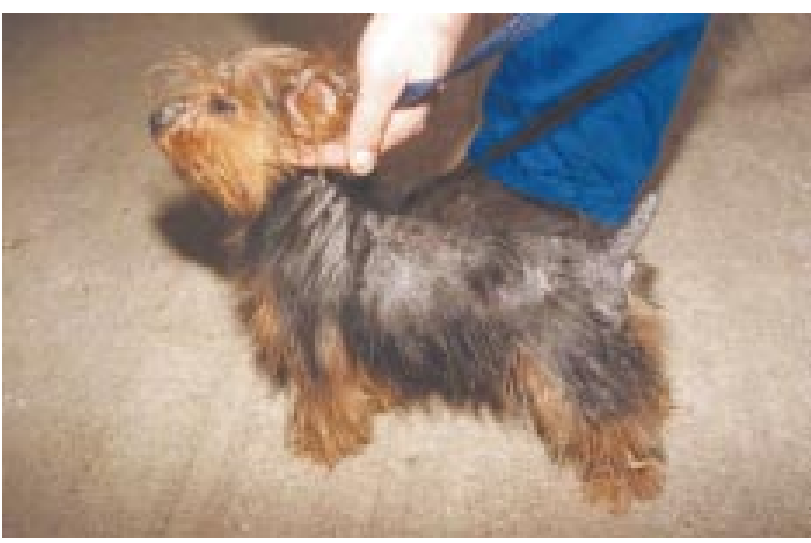

Figura 1. Dermatofitose. Yorkshire, fêmea, 2 anos. Lâmpada de Wood: positiva. Microscopia direta: positiva para artroconídios. Cultura fúngica: Microsporum canis.

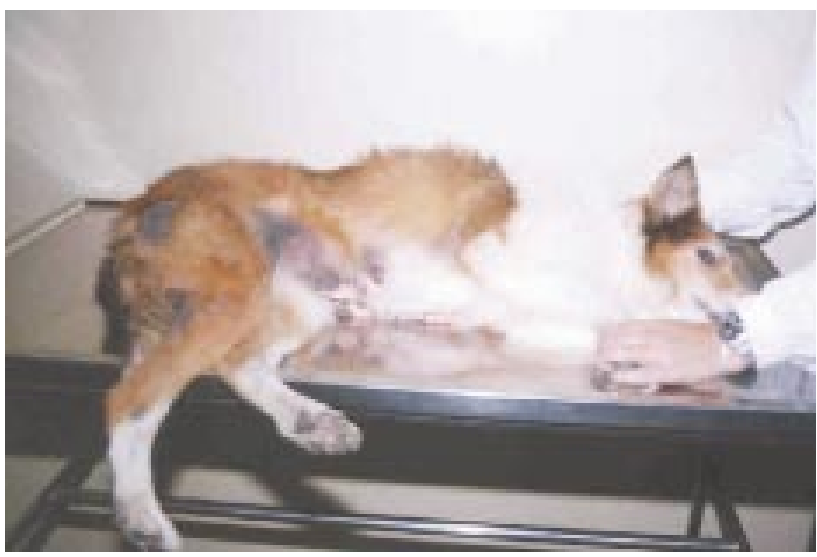

Figura 3. Atopia. Collie, fêmea, 6 anos. Lâmpada de Wood e microscopia direta: negativas. Cultura fúngica: Microsporum gypseum.

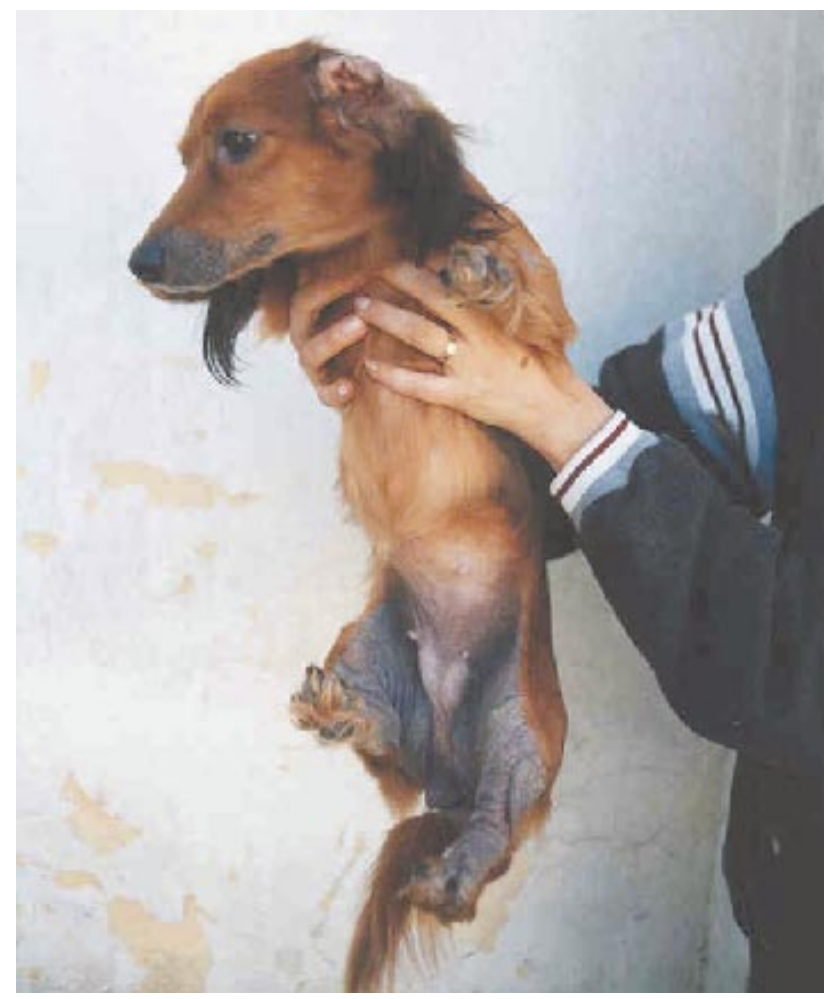

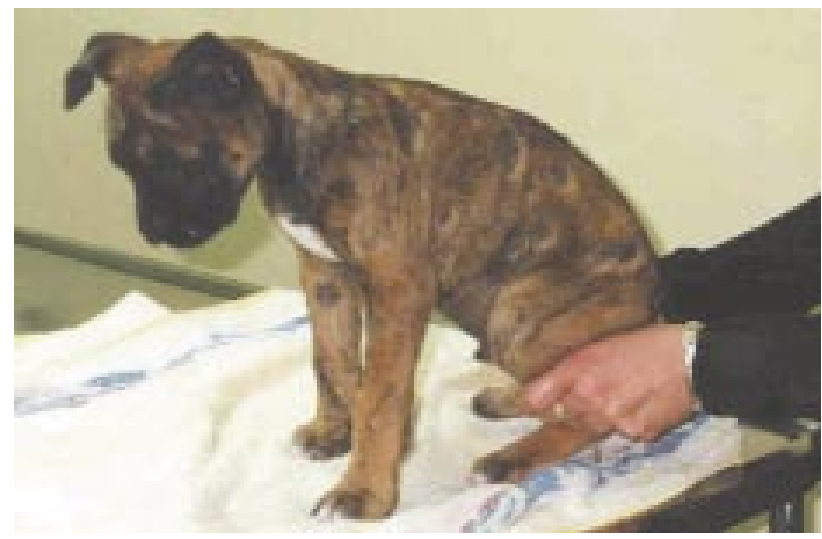

Figura 2. Dermatofitose. Boxer, macho, 3 meses. Lâmpada de Wood: negativa. Microscopia direta: positiva para artroconídios. Cultura fúngica: Microsporum canis.

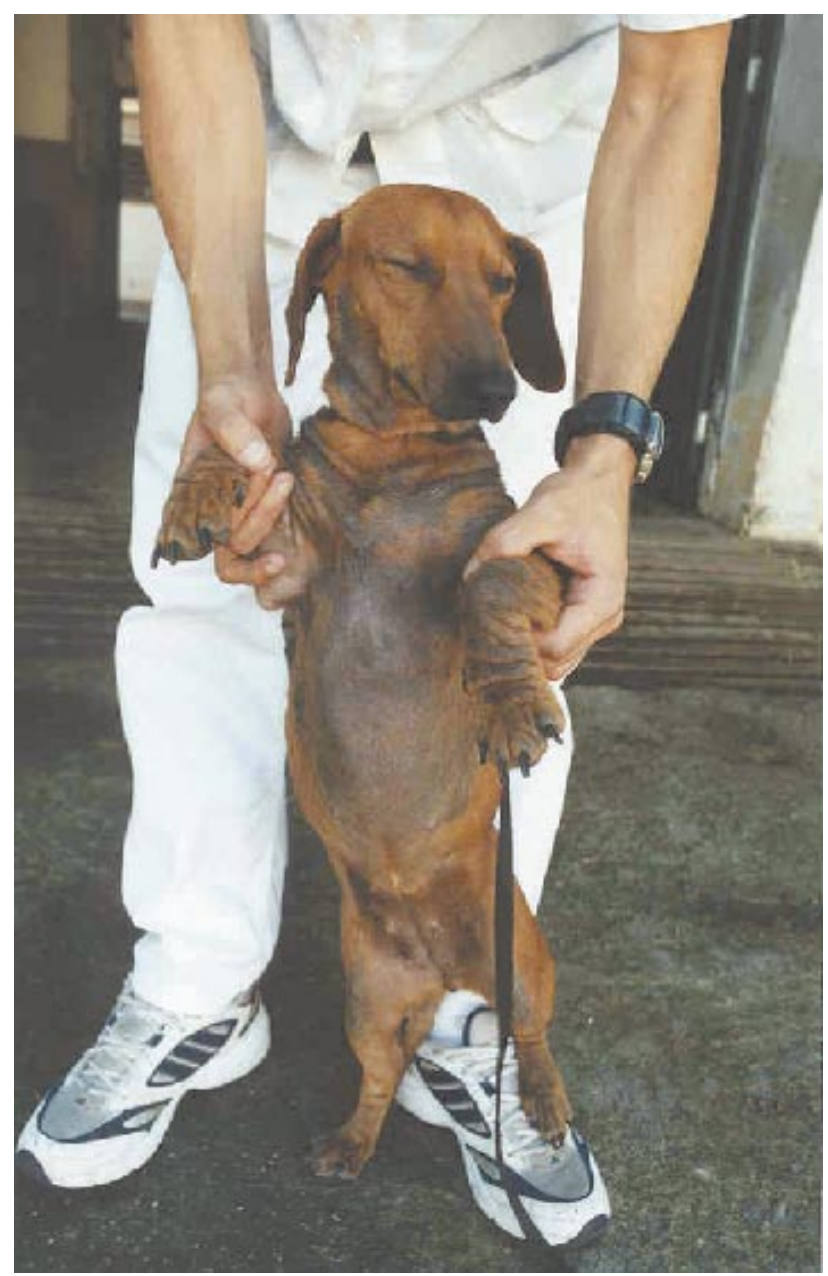

Figura 4. Demodicidose: Dachshund, fêmea, 1,5 anos. Lâmpada de Wood: negativa. Microscopia direta: ácaros de Demodex canis. Cultura fúngica: Malassezia pachydermatis.

Figura 5. (à esquerda) Acantose nigricante. Dachshund, fêmea, 4 anos. Lâmpada de Wood e microscopia direta: negativas. Cultura fúngica: Malassezia pachydermatis. 
em somente nas duas primeiras raças mencionadas. Estes dados concordam com vários autores $[4,10,12,16,18,20]$ que observaram essas raças como sendo as mais freqüentemente afetadas por dermatite por Malassezia; além de citarem outras, como a Basset Hound, Yorkshire, Fox Terrier, Shar Pei, West Highland Terrier, etc., que no presente trabalho não foram muito representativas.

Em 97\% dos cães com M. pachydermatis, foi diagnosticada uma dermatopatia concomitante, sendo que, em apenas um indivíduo, observou-se somente a dermatite por Malassezia, curada com a utilização de terapia antifúngica. Este fato está de acordo com autores [5,11], que citam o tratamento antifúngico e a resposta terapêutica positiva como parâmetros para o diagnóstico final de malasseziose.

Os porcentuais de $M$. pachydermatis, encontrados neste trabalho, foram mais expressivos em cães que tiveram, como diagnóstico das dermatopatias, as seguintes doenças, mencionadas em ordem decrescente de representatividade: atopia, disqueratinizações, dermatite alérgica à picada de pulgas, demodicidose e foliculite bacteriana. Neste trabalho, 39,5\% das culturas de M. pachydermatis advieram de cães com quadro clínico compatível com atopia, detectando-se, nesta associação, diferença estatística significante $(p<0,05)$ em relação às demais culturas dessa levedura advindas de cães com outras dermatopatias. Este dado está em concordância com a maioria dos trabalhos consultados $[5,8,14]$, nos quais a atopia foi citada como a principal doença associada à $M$. pachydermatis, apesar de outros autores [4] num estudo posterior, relatarem que a pele de cães atópicos não deve ser mais favorável ao desenvolvimento de $M$. pachydermatis, do que a pele de cães com outras dermatopatias.

De qualquer forma, a avaliação da presença de $M$. pachydermatis, em cães com dermatites com as características acima descritas, deve ser realizada de forma rotineira, por citologia ou cultura fúngica, e o tratamento antifúngico deve ser considerado quando da sua constatação.

\section{CONCLUSÕES}

Conforme os diagnósticos das dermatopatias e os resultados das culturas fúngicas advindas dos 250 cães utilizados neste trabalho, podemos concluir que: 1. As dermatopatias mais freqüentemente diagnosticadas nos 250 animais estudados pertenceram ao grupo das doenças de origem imunopática, enquanto as menos freqüentes pertenceram ao grupo de origem endócrina.

2. A maior ocorrência dos diagnósticos finais das dermatopatias, dos 250 cães amostrados, em ordem decrescente de representatividade foram: a dermatite alérgica à picada de pulgas, a atopia, as disqueratinizações, a demodicidose, a escabiose, a dermatofitose e a foliculite bacteriana.

3. A ocorrência de fungos causadores de micoses cutâneas, em cães com dermatopatias diversas, foi de $20,8 \%$, distribuídos em 7,6\% de dermatófitos (73,7\% Microsporum canis e 26,3\% M. gypseum) e 13,2\% de leveduras (100\% Malassezia pachydermatis).

4. Nos cães, cujas culturas resultaram positivas para dermatófitos, não houve aparente predisposição sexual ou etária; entretanto, quanto à definição racial, cães da raça Yorkshire mostraram-se, estatisticamente, significantes $(\mathrm{p}<0,05)$.

5. Dentre as culturas positivas para leveduras, a única espécie encontrada foi Malassezia pachydermatis que, na maioria dos casos $(97,0 \%)$, estava associada a uma dermatopatia primária, como a atopia, que foi a única com significância estatística.

6. A malasseziose primária foi de baixa prevalência (1caso).

7. Não houve aparente predisposição sexual ou etária em relação à população amostrada e às culturas de M. pachydermatis.

8. Quanto à predisposição racial, observou-se maior porcentual de culturas positivas de M. pachydermatis em cães sem raça definida. Entre os com perfeita definição racial - Dachshund, Pastor Alemão, Cocker - foi comprovada significância estatística somente para as duas últimas raças. 


\section{REFERÊNCIAS}

1 Al-Doory Y., Vice T.E. \& Olin D.V.M. 1968. A survey of ringworm in dogs and cats. Journal of the American Veterinary Medical Association. 153: 429-432.

2 Batista Júnior J. A. \& Nico F. 1967. Incidência do Microsporum canis em cães de Belo Horizonte. Arquivos da Escola de Veterinária da UFMG. 9: 89-92.

3 Bone W. J. \& Jackson W. F. 1971. Pathogenic fungi in dermatitis - incidence in two small animal practices in Florida. Veterinary Medicine / Small Animal Clinician. 66: 140 - 142.

4 Bond R., Fergunson E. A., Curtis C. F., Craig J. M. \& Lloyd D. H. 1996. Factors associated with elevated cutaneous Malassezia pachydermatis populations in dogs with pruritic skin disease. Journal of Small Animal Practice. 37: 103-107.

5 Bond R. 1997. Malassezia pachydermatis y enfermedad dermatológica canina. Walthan Foccus. 7: 27-31.

6 Ferreiro C. L. R., Berg V., Quadrado S. S. \& Ferreiro L. 1997. Comparação da incidência dos agentes etiológicos das dermatomicoses dos carnívoros domésticos na região da Grande Porto Alegre - RS (Brasil) entre os períodos 1979/82 e 1996/97. In: Anais do XXV Congresso Brasileiro de Medicina Veterinária (Gramado, Brasil). p. 152.

7 Gambale W., Correa B., Paula C. R., Purchio A. \& Larsson C.E. 1997. Ocorrência de fungos em lesões superficiais de cães na cidade de São Paulo, Brasil. Revista da Faculdade de Medicina Veterinária e Zootecnia da Universidade de São Paulo. 24: 187-192.

8 Guaguere E. \& Prelaud P. 1996. A retrospective study of 54 dogs with Malassezia pachydermatis dermatitis: epidemiological, clinical, cytological and histological results. Pratique Médicale et Chirurgicale de l'Animal de Compagnie. 31: 309-323.

9 Kiss G., Radvanyi S. \& Szigeti G. 1993. Incidence of Malassezia pachydermatis yeast. III. Malassezia dermatitis in dogs. Magyar-AllatorvosokLapja. 48: 548-553.

10 Larsson C.E., Larsson M.H.M.A. \& Amaral R.C. 1988. Dermatitis in dogs caused by Malassezia (Pityrosporum) pachydermatis. Ars Veterinaria.4: 63-68.

11 Mason K. V. \& Evans A.G. 1991. Dermatitis associated with Malassezia pachydematis in 11 dogs. Journal of the American Animal Hospital Association. 27: 13-20.

12 Mauldin E.A., Scott D.W, Miller Jr. W.H. \& Smith C.A.1997. Malassezia dermatitis in the dog: a retrospective histopathological and immunopathological study of 86 cases. Veterinary Dermatology. 3: 191-202.

13 Meneses A.M.C., Ardoso M.J.L., Franco S.R.V.S \& Abe K.C. 2000. Ocorrência das dermatopatias em cães e gatos. Revista Brasileira de Ciência Veterinária. 7 (Suppl): 90.

14 Morris D.O., Olivier N.B. \& Rosser E.J. 1998. Type-1 hypersensibility reactions to Malassezia pachydermatis extracts in atopic dogs. American Journal of Veterinary Research. 59: 836-841.

15 Nagata M. \& Sakai T. 1999. Clinical survey of canine dermatosis in Japan. Journal of the Japan Veterinary Medical Association. 52: 775-779.

16 Nesbitt G. H. \& Ackerman L. J. 1998. Canine and feline dermatology. New Jersey: Veterinary Learning Systems, 498 p. 17 Nobre M.O., Meireles M.C.A., Gaspar L. F., Pereira D., Schramm R., Schuch L. F., Souza L. \& Souza L.1998. Malassezia pachydermatis e outros agentes infecciosos em otites externas e dermatites em cães. Ciência Rural. 28: 447-452.

18 Pedersen K. 1992. Seborrheic dermatitis in 10 dogs caused by Malassezia pachydermatis. A overlooked problem. Dansk - Veternaertidsskrift. 75: 513-520

19 Pinard M., Chermette R. \& Bussiéras S. 1987. Diagnostic et prophylaxie des teignes des carnivores domestiques - Étude critique à partir d'une enquête à l'Ecole National Vétérinaire d'Alfort. Recueil de Médecine Vétérinaire. 163: 1107-1116.

20 Plant J.D., Rosenkrantz W.S. \& Griffin C.E. 1992. Factors associated with and prevalence of high Malassezia pachydermatis numbers on dog skin. Journal of the American Veterinary Medical Association. 201: 879 - 882.

21 SAME-HCV. 1999. Serviço Médico e Estatístico do Hospital de Clínicas Veterinárias da UFRGS. Porto Alegre, RS, Brasil. 
22 Scott D. W., Miller W. H. \& Griffin C. E. 1990. Muller \& Kirk, Dermatologia de pequenos animais. 5.ed. São Paulo: Interlivros, $1130 \mathrm{p}$.

23 Scott D. W. \& Paradis M. 1990. A survey of canine and feline skin disorders seen in a university practic. Small Animal Clinic ,University of Montréal, Saint- Hyacinthe, Québéc, (1987-1988). Canadian Veterinary Journal. 31 : $830-835$.

24 Van Cutsem J., Keyser, H. D.E, Rochette F. \& Van Der Flaes M. 1985. Survey of fungal isolates from alopecic and asymptomatic dogs. The Veterinary Record. 25: 568 - 569.

25 Willense T. 1992. Un enfoque diagnóstico del perro y el gato com prurito. Whaltan Internacional Focus. 2: 2. 